William R. Wiley

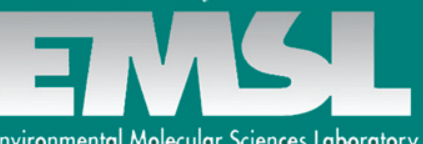

Environmental Molecular Sciences Laboratory

(20)

\title{
Simulation of Climate Forcing by Aerosols
}

S.J. Ghan

X. Bian

E.G. Chapman

R.C. Easter

G.I Fann

S.C. Kothari

R. Zaveri

Y. Zhang

May 2004 


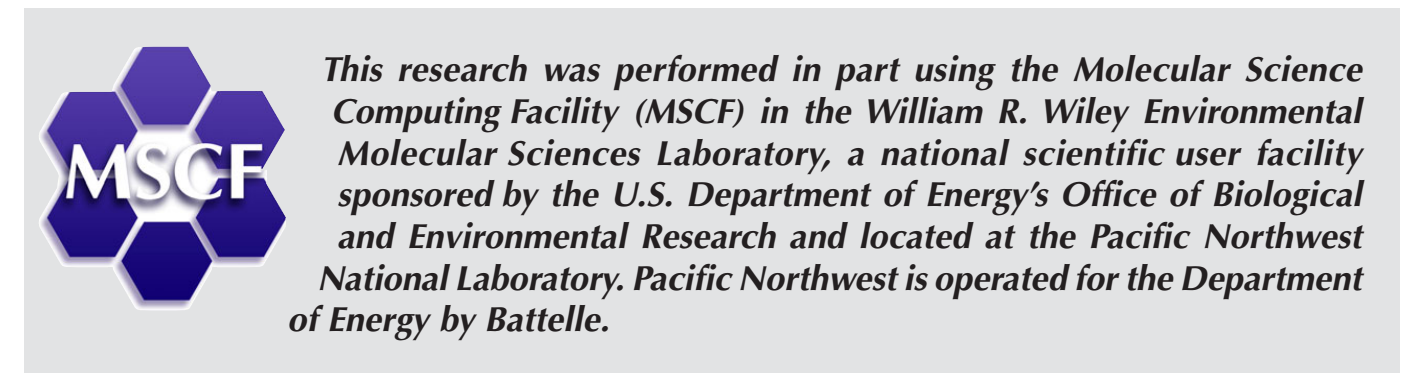

\title{
DISCLAIMER
}

This report was prepared as an account of work sponsored by an agency of the United States Government. Neither the United States Government nor any agency thereof, nor Battelle Memorial Institute, nor any of their employees, makes any warranty, express or implied, or assumes any legal liability or responsibility for the accuracy, completeness, or usefulness of any information, apparatus, product, or process disclosed, or represents that its use would not infringe privately owned rights. Reference herein to any specific commercial product, process, or service by trade name, trademark, manufacturer, or otherwise does not necessarily constitute or imply its endorsement, recommendation, or favoring by the United States Government or any agency thereof, or Battelle Memorial Institute. The views and opinions of authors expressed herein do not necessarily state or reflect those of the United States Government or any agency thereof.

\author{
PACIFIC NORTHWEST NATIONAL LABORATORY \\ operated by \\ BATTELLE \\ for the \\ UNITED STATES DEPARTMENT OF ENERGY \\ under Contract DE-ACO6-76RLO183O
}

http://www.pnl.gov/main/publications/external/technical_reports/pnnl-14634.pdf

PNNL-14634, Published by Pacific Northwest National Laboratory for the Environmental Molecular Sciences Laboratory 


\title{
Simulation of Climate Forcing by Aerosols
}

\author{
S.J. Ghan \\ X. Bian \\ E.G. Chapman \\ R.C. Easter \\ G.I. Fann \\ S.C. Kothari \\ R. Zaveri \\ Y. Zhang
}

May 2004

Published by Pacific Northwest National Laboratory for the Environmental Molecular Sciences Laboratory 


\section{Table of Contents}

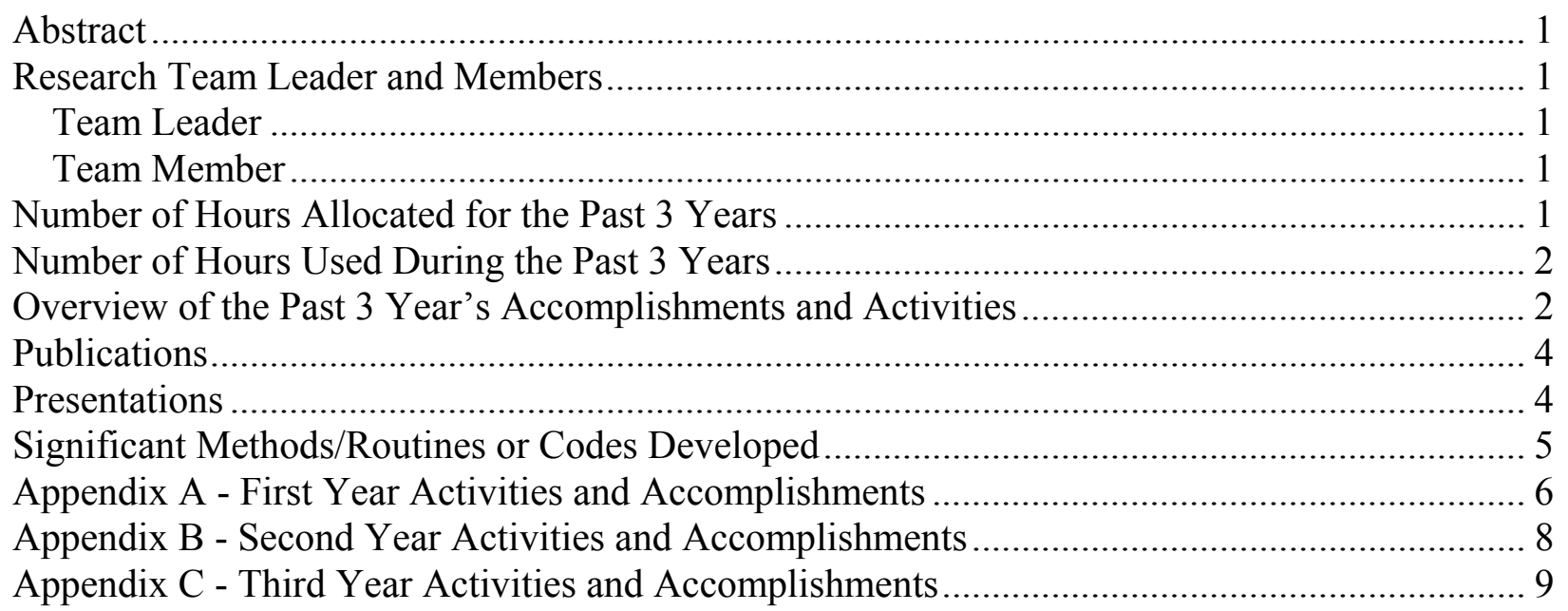




\title{
Simulation of Climate Forcing by Aerosols
}

\begin{abstract}
$\underline{\text { Abstract }}$
The largest source of uncertainty in estimates of the radiative forcing governing climate change is in the radiative forcing due to anthropogenic aerosols. Current estimates of the global mean of the aerosol radiative forcing range from -0.3 to -3.0 watts per square meter $\left(\mathrm{Wm}^{-2}\right)$, which is opposite in sign and possibly comparable in magnitude to the $+2 \mathrm{Wm}^{-2}$ forcing due to increasing greenhouse gases. The team developed a global aerosol and climate modeling system that provides the most detailed treatment of aerosols and their impact on the planetary radiation balance of any model. However, estimates of radiative forcing have been hindered by lack of access to high-performance computing resources. The team proposes to use the Molecular Science Computing Facility (MSCF) to conduct a series of simulations with and without emissions of a variety of aerosol particles and aerosol precursors. These extensive simulations will enable team members to produce more refined estimates of the impact of anthropogenic emissions on radiative forcing of climate change. To take full advantage of the parallelism available on the MSCF MPP1, the Global Array Toolkit will be used to dynamically load balance the reactive chemistry component of the modeling system. Team members will adapt their modifications of the serial National Center for Atmospheric Research (NCAR) Community Climate Model (CCM2) to the parallel NCAR CCM3.10.
\end{abstract}

\section{$\underline{\text { Research Team Leader and Members }}$}

Team Leader

Name: S. J. Ghan

Institution: Pacific Northwest National Laboratory

$\underline{\text { Team Member }} \quad \underline{\text { Institution }}$

G. I. Fann Pacific Northwest National Laboratory

R. C. Easter Pacific Northwest National Laboratory

X. Bian Pacific Northwest National Laboratory

S. C. Kothari Iowa State University

R. Zaveri Pacific Northwest National Laboratory

E. G. Chapman Pacific Northwest National Laboratory

Y. Zhang Atmospheric and Environmental Research

Number of Hours Allocated for the Past 3 Years

Year 1: 188,000

Year 2: 121,000

Year 3: 204,000

Total: 513,000 


\section{Number of Hours Used During the Past 3 Years}

Year 1: 50,000

Year 2: 40,000

Year 3: 42,000

Total: 132,000

\section{Overview of the Past 3 Year's Accomplishments and Activities}

The primary project goal was to use the IBM SP2 ${ }^{\circledR}$ time to run production simulations with the global aerosol code. Due to circumstances beyond control, the team did not achieve this goal. Until recently, team members were using a serial version of their global aerosol code on workstations. Initially members tried parallelizing this code on their own, and made considerable progress parallelizing the chemistry and aerosol component of the code. However, the team concluded the climate component of the code should not be parallelized because there is an independent Scientific Discovery Through Advanced Computing (SciDac)/National Science Foundation effort to parallelize the code (NCAR Community Atmosphere Model [CAM], previously known as CCM) that could serve as the framework for the global aerosol model. The team decided to wait for the release of a parallel version of CAM and then apply its chemistry and aerosol physics to it. In the meantime, team members improved their model physics. However, release of the parallel version of CAM was delayed 3 years until May 2002. The team was therefore unable to use any of its MSCF allocation for the global aerosol simulations.

Although the May 2002 CAM release date was disappointing, it had two key advantages. First, the team obtained permission from NCAR to pursue development of a subgrid orography scheme in CAM. With the MSCF allocation, members performed all simulations needed to form the basis for a journal article. The article describes the first global climate simulations that provide climate information at $5 \mathrm{~km}$ resolution, far finer than has ever been previously considered. The MSCF time on the IBM SP2 ${ }^{\circledR}$ has proven essential for this project. The journal article was published in Climate Dynamics, which has an impact factor of 4.7. Following article preparation, the team performed a higher resolution (1.4) simulation without the subgrid orography scheme. Comparing the higher resolution no-subgrid simulation with a lower resolution (2.8) simulation with the subgrid scheme demonstrates the benefits of parameterizing subgrid orography comparing with trying to resolve it explicitly (Figure 1). Shortly after the higher resolution simulation was complete, the team released the remainder of its MSCF allocation for others to use.

A second advantage of the delayed CAM release was that the released version offers more efficiency features. It includes the product of a large intensive U.S. Department of Energy (DOE)-funded parallelization effort to improve modularity, portability, parallel efficiency, multithreading, and flexibility of domain decomposition. Most notable is the introduction of two-dimensional domain decomposition, which permits simulations on more than the 64 nodes allowed by earlier CAM versions. By waiting for the development of these improvements in the modeling framework, the team can leverage the work of the DOE SciDAC Climate Project and ultimately make better use of the MSCF. 

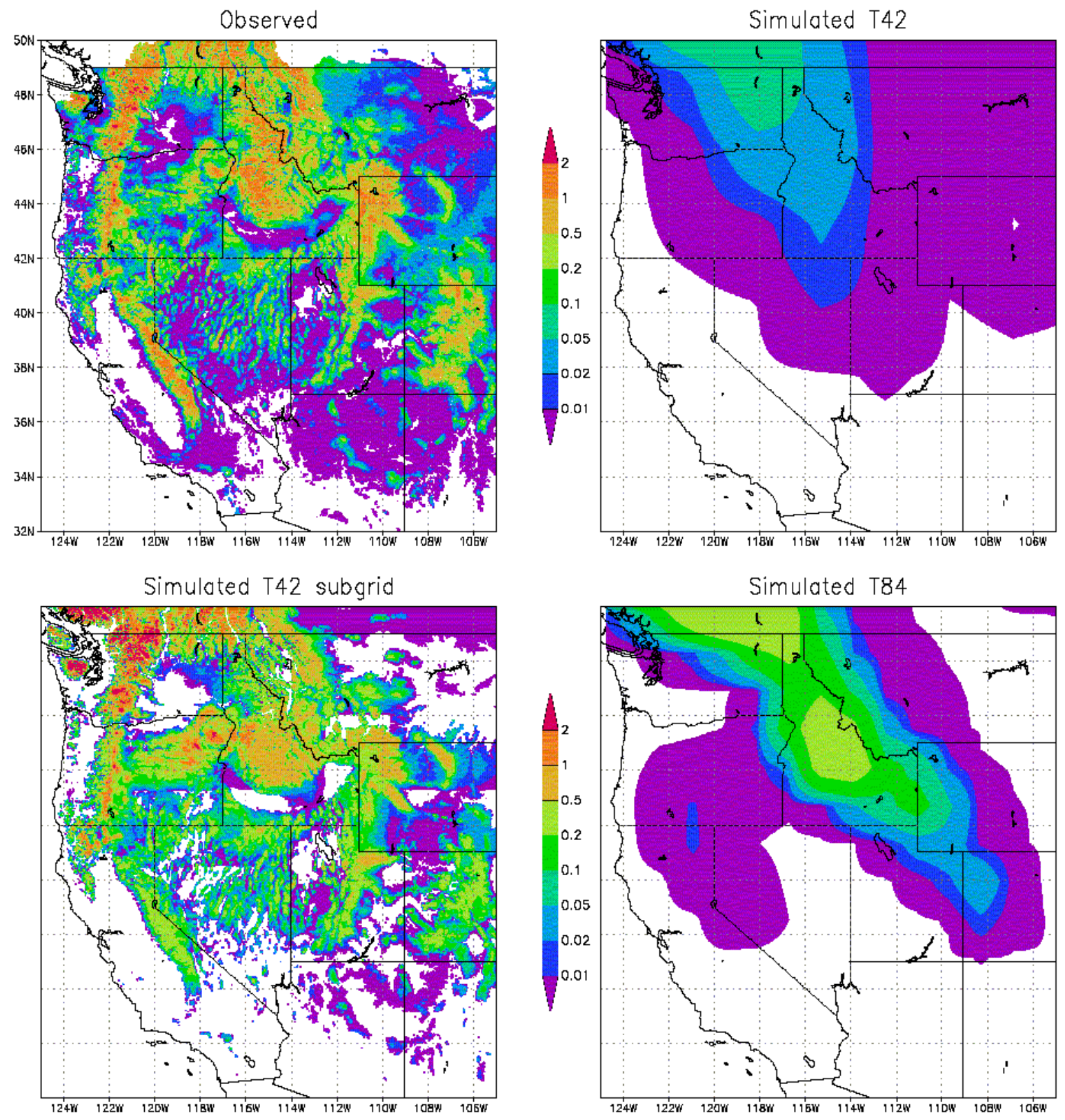

Figure 1. Distribution of snow water equivalent $(\mathrm{m})$ in the western United States during March as observed, as simulated by CAM at T42 (2.8 latitude and longitude) resolution with the subgrid scheme, as simulated at T42 resolution without the subgrid scheme, and as simulated at T84 $\left(1.4^{\circ}\right)$ resolution without the subgrid scheme. 
The team continues work on aerosol/chemistry modeling. Three journal articles were published describing the estimate of aerosol radiative forcing using the first generation of the global aerosol model. Team members also prepared for the application of cloud and aerosol modifications to the CAM by applying their cloud mods to an earlier CAM version (not to be used for production experiments). Members also embedded their aerosol and chemistry code within CAM rather than coupling the aerosol and chemistry code with CAM via common blocks. The latter decision greatly simplified the coordination of the domain decomposition and communication between the chemistry/aerosol physics, cloud physics, and fluid mechanics in the model, and allows the use of parallelization being developed by the DOE SciDAC team. Since the CAM has been released, the team has been busy applying its chemistry, aerosol, and cloud physics to it in preparation for a new generation of global aerosol simulations.

\section{$\underline{\text { Publications }}$}

Bian, X, RC Easter, G Fann, JD Fast, R Zaveri, and C Berkowitz. 2000. 'PNNL's PEGASUS Advances Atmospheric Modeling of Ozone; EMSL MSCF Project: Software Development of Atmospheric Chemistry." Available URL: http://mscf.emsl.pnl.gov/research/pegasus.shtml.

Easter, RC, SJ Ghan, Y Zhang, RD Saylor, EG Chapman, NS Laulainen, H Abdul-Razzak, LR Leung, X Bian and RA Zaveri. 2003. MIRAGE: Model Description and Evaluation of Aerosols and Trace Gases, J. Geophys. Res., submitted.

Ghan, SJ, X Bian, AG Hunt, and A Coleman. 2002. "The Thermodynamic Iinfluence of Subgrid Orography in a Global Climate Model.” Climate Dynamics. 20:31-44.

Ghan, SJ, RC Easter, E Chapman, H Abdul-Razzak, Y Zhang, LR Leung, N Laulainen, R Saylor and R Zaveri. 2001. "A Physically-Based Estimate of Radiative Forcing by Anthropogenic Sulfate Aerosol.” J. Geophys. Res. 106:5279-5293.

Ghan, SJ, RC Easter, J Hudson, and FM Breon. 2001. "Evaluation of Aerosol Indirect Radiative Forcing in MIRAGE.” J. Geophys. Res. 106:5317-5334.

Ghan, S, N Laulainen, R Easter, R Wagener, S Nemesure, E Chapman, Y Zhang, and R Leung. 2001. "Evaluation of Aerosol Direct Radiative Forcing in MIRAGE." J. Geophys. Res., 106:5295-5316.

\section{$\underline{\text { Presentations }}$}

Ghan SJ. 2001. "Global Climate Simulation at 5 km Resolution." Presented by Steven J. Ghan at the NASA Investigator Working Group Meeting, San Antonio, Texas on November 1, 2001. PNNL-SA-40216, Pacific Northwest National Laboratory, Richland, Washington.

Ghan SJ, and TR Shippert. 2002. "Application of a Subgrid Orography Scheme to a Global Climate Model." Presented by Steven J. Ghan at the Seventh Annual Community Climate System Model Workshop, Breckenridge, Colorado on June 25, 2002. PNNL-SA-40086, Pacific Northwest National Laboratory, Richland, Washington. 
Ghan SJ, X Bian, A Coleman, and AG Hunt. 2001. "Application of a Subgrid Orography Scheme to a Global Climate Model." Presented by Steven J. Ghan at the Sixth Annual Community Climate System Model Workshop, Breckenridge, Colorado on June 26, 2001. PNNL-SA-40214, Pacific Northwest National Laboratory, Richland, Washington.

Ghan SJ, EG Chapman, RC Easter, J Reid, and C Justice. 2003. "Simulation of the Intercontinental Transport, Aging, and Removal of a Boreal Fire Smoke Plume." Presented by Steven J. Ghan at 2003 American Geophysical Union Fall Annual Meeting, San Francisco, California on December 9, 2003. PNNL-SA-40611, Pacific Northwest National Laboratory, Richland, Washington.

\section{Significant Methods/Routines or Codes Developed}

- Significant changes to CAM, adding cloud microphysics, boundary layer turbulence, aerosol physics, and tropospheric chemistry.

- Application of a subgrid orography scheme to CAM. 


\section{Appendix A - First Year Activities and Accomplishments}

The primary goal for the first year was to get the code running efficiently on the IBM SP2®. Four steps were involved:

1. Improve the efficiency of the chemistry code global chemistry model (GChM).

2. Improve the efficiency of the meteorology code CCM.

3. Couple the chemistry and meteorology codes.

4. Improve the efficiency of the coupled codes.

Good progress was made in the first three tasks; the fourth task has not yet been addressed.

The efficiency of the chemistry code PEGASUS (the regional cousin of the global chemistry code GChM) was greatly improved, with the speedup improved from about 30 to about 160 (see Figure A.1). This was accomplished by parallelizing the horizontal transport and implementing load balancing. More details are explained in Bian et al. 1999; 2000a; 2000b.

The efficiency of the meteorology code CCM was improved by replacing the serial code CCM2 with the parallel code CCM3.10. This task involved translating all of the team's modifications of CCM2 (the addition of cloud physics, prediction of turbulent kinetic energy, treatment of aerosol radiative properties) to CCM3.10. This task is not yet complete because CCM3.10 was released June 20, 2000. However, the same modifications were successfully applied to an earlier parallel version CCM3.6, and timing simulations were performed on the MSCF SP2. The team decided to repeat the translation again for CCM3.10 because it offered much more portability than CCM3.6.

The coupling of the chemistry and meteorology codes was achieved for version CCM3.6, and serial simulations were performed. However, parallel simulations were not performed because of portability problems. Coupling of the chemistry and meteorology codes involves modifying $\mathrm{CCM}$ to store all of the meteorology fields required by the GChM and to use the aerosol fields (produced by the GChM) to determine cloud droplet number and radiative heating rates. Coupling of GChM with CCM3.10 is not yet complete because of the late release of CCM3.10, but is proceeding rapidly. 


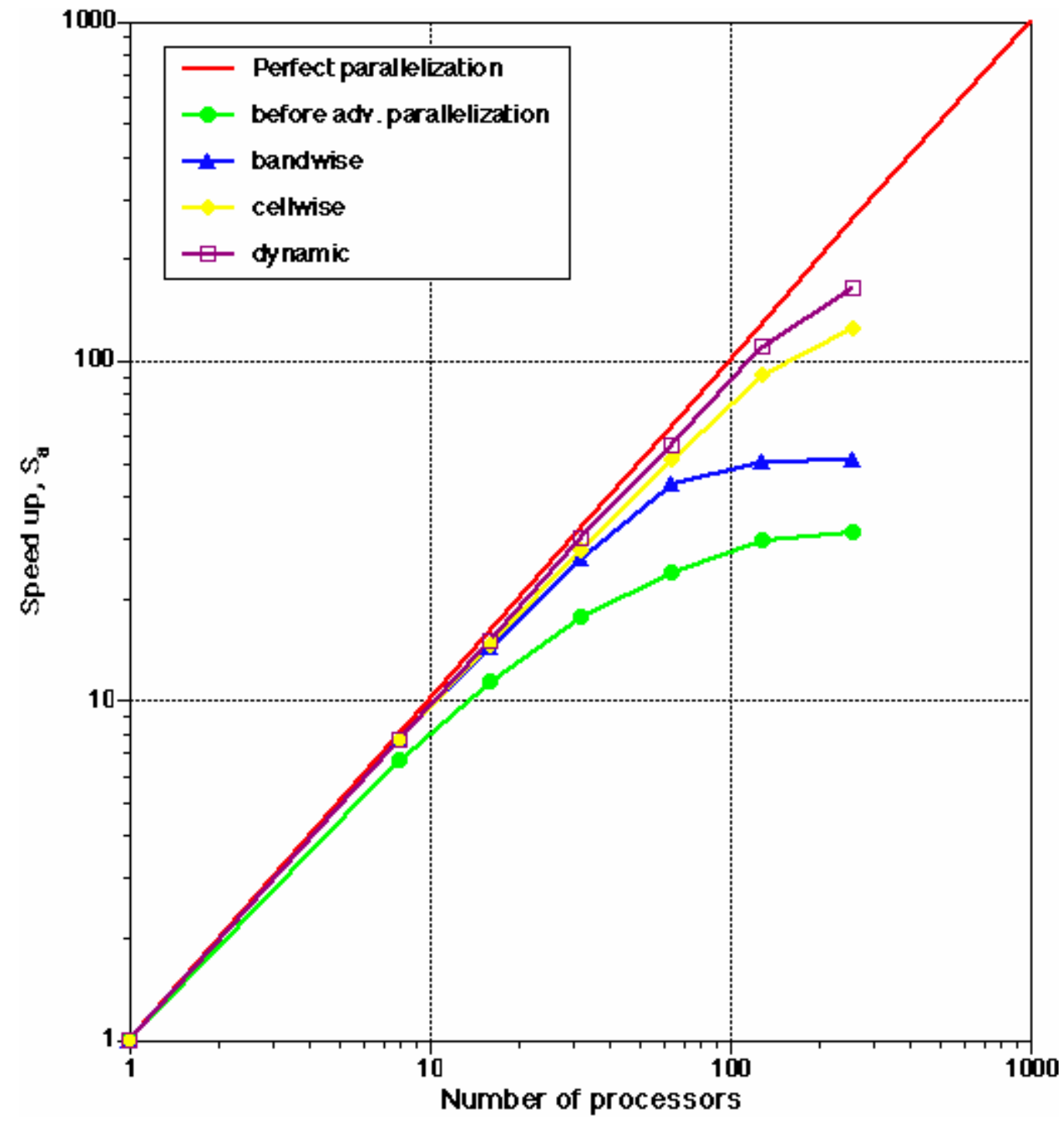

Figure A.1. Speedup of the PNNL Atmospheric Chemistry Code as a Function of Processors on the MSCF SP2. 


\section{Appendix B - Second Year Activities and Accomplishments}

The team has continued work on its aerosol/chemistry modeling work. With the release of CAM2, we have applied our treatment of chemistry, aerosol, and cloud physics to it in preparation for a new generation of global aerosol simulations. The new physics is very similar to that described in papers on the previous (serial) version of this model (Ghan et al., 2001a,b,c; Easter et al., 2003). The aerosol is represented by four log-normal size distributions, each composed of a mixture of sulfate, organic carbon, black carbon, seasalt, and soil dust. Treatments of emissions, transport, gas-phase and aqueous phase oxidation, nucleation, condensation, coagulation, hydration, activation, autoconversion, resuspension, gravitational settling, precipitation scavenging have been introduced within CAM2. Two experiments have been performed, one an evaluation of the global aerosol simulation as part of the AEROCOM project (http://nansen.ipsl.jussieu.fr/ AEROCOM/aerocomhome.html), the other a simulation of the global dispersion of smoke from intense forest fires in Siberia. The latter was presented at the 2003 Fall Meeting of the American Geophysical Union. 


\section{Appendix C - Third Year Activities and Accomplishments}

The primary goal for the project was to use the IBM SP $2 \circledR$ time to run production simulations with the global aerosol code. Due to uncontrollable circumstances, the team did not achieve that goal. Until recently, the team had been using a serial version of its global aerosol code on workstations. Although team members considered parallelizing this code on their own, they quickly realized that a far better use of their time would be to focus on improving model physics and wait for the results of an independent SciDAC/NSF effort to parallelize the code (the NCAR CAM) that would serve as the framework for the global aerosol model. Release of the parallel code was delayed 3 years until May 2002. The team was therefore unable to use any of its MSCF allocation for the global aerosol simulations.

Although the May 2002 release date was disappointing, it had two key advantages. First, the team obtained permission from NCAR to pursue the development of a subgrid orography scheme in CAM. During 2001, members completed that task and performed most of the simulations needed to form the basis for a journal article. The article describes the first global climate simulations that provide climate information at $5 \mathrm{~km}$ resolution, far finer than has ever been previously considered. The MSCF time on the IBM SP2 ${ }^{\circledR}$ proved essential for this work; the Linux cluster did not have a communication system reliable enough for the simulations. The journal article will be published soon in Climate Dynamics, which has an impact factor of 4.7. Following article preparation, the team also performed a high-resolution $(140 \mathrm{~km})$ simulation without the subgrid orography scheme. Comparing the high resolution no-subgrid simulation with a lower resolution $(280 \mathrm{~km})$ simulation with the subgrid scheme demonstrates the benefits of parameterizing subgrid orography comparing with trying to resolve it explicitly.

A second advantage of the delayed CAM release was that the released version offered more efficiency features. It included the product of a large intensive DOE-funded parallelization effort to improve modularity, portability, parallel efficiency, multithreading, and flexibility of domain decomposition. Most notable was the introduction of two-dimensional domain decomposition, which permits simulations on more than the 64 nodes allowed by earlier versions of CAM. By waiting for the development of these improvements in the modeling framework, the team can leverage the work of the DOE SciDAC Climate Project and ultimately make better use of the MSCF.

The team has continued work on its aerosol/chemistry modeling work. Now that CAM has been released, the team is busy applying its chemistry, aerosol, and cloud physics to it in preparation for a new generation of global aerosol simulations. 